\title{
A Study on The Formulation of Plant Matrix Tablets From Coarse Botanical Materials Using Cinnamon Bark and Areca Nut as The Model Botanical Materials
}

\author{
Natalia Veronica, Xiu Hui Ang, Shing Ming Ooi, Celine Valeria Liew, Paul Wan Sia Heng* \\ GEA-NUS Pharmaceutical Processing Research Laboratory, Department of Pharmacy, National University of Singapore, Singapore
}

\section{ARTICLE HISTORY}

Received: June 2019

Revised: October 2019

Accepted : August 2020

\begin{abstract}
Background: There is much interest in formulating botanical materials into tablets due to the compactness and ease of administration. However, tableting of coarse milled botanical materials poses a challenge due to poor tableting properties. Objective: To evaluate the feasibility of wet granulation to produce tablets from coarse milled botanical materials and to assess the effect of formulation on properties of the tablets. Materials and Methods: Cinnamon bark and areca nut were milled to obtain 1-2 $\mathrm{mm}$ particle size, which was subsequently used in wet granulation using maltodextrin solution as a granulating liquid. Two diluents were tried; microcrystalline cellulose (MCC) or mannitol at a different ratio to the botanical materials. Tablets were then produced from the granules and evaluated for tensile strength and surface roughness. Results: Tablets formulated with MCC had higher tensile strength than tablets formulated with mannitol. Additionally, granules prepared using mannitol were more friable than those with MCC. The effect of diluent to botanical material ratio was more prominently observed on tablet surface roughness. Tablets containing a higher ratio of botanical material had a rougher surface, which could have implications on the mouth-feel of the tablets. Conclusion: Wet granulation could be a viable pre-processing method to produce tablets from coarse milled botanical materials.
\end{abstract}

Keywords: coarse botanical materials; tablets; wet granulation; milling *corresponding author

Email: phapaulh@nus.edu.sg

\section{INTRODUCTION}

Botanical materials are known to contain therapeutic properties owing to various complex chemical substances of different compositions. Oral delivery of botanical materials is available in diverse dosage forms, including tablets, capsules, tinctures, syrups, and powders (Alamgir, 2017). Among these, tablets offer the convenience of administration, ease of handling, and transportation as well as relatively greater physical and chemical stability as compared to other dosage forms such as syrups and suspensions. As such, there is an increasing interest in formulating botanical materials into tablets.

In order to formulate botanical materials into tablets, the materials need to be processed into suitable forms for tableting. Such processing includes milling and extraction (Parikh, 2016; Yi et al., 2011). Extraction typically involves water or organic solvents. Consequently, extraction is relatively more costly and tedious than milling. Nonetheless, tablets can be prepared either from the extracts or milled botanical materials (Chandira et al., 2010; Cvetanovic et al., 2011; Sun et al., 2016). In order to form tablets of appreciable mechanical strength for handling and transportation, a certain degree of bonding is required between the botanical materials.
Such bonding, however, is lacking if the tablets were to be made of solely botanical materials. Therefore, although direct compression is the preferred choice for tablet manufacturing, poor tableting properties of most botanical materials render direct compression to be challenging (Li et al., 2018).

Alternatively, the processed botanical materials can be subjected to granulation. For example, granules can be prepared from leonurus, crataegus, and ginkgo extracts as well as ginkgo, echinacea, and mentha extracts (Bernatoniene et al., 2010; Cvetanovic et al., 2011). Granulation is a particle enlargement process through the agglomeration of coarse fine particles to larger agglomerates known as granules. The granulation technique can be broadly classified into two types; wet and dry granulation. Wet granulation involves the addition of a granulating liquid to a powder bed to agglomerate particles. In contrast, dry granulation agglomerates particles through the use of high compression pressure without any liquid solvent (Shanmugam, 2015). Process parameters such as viscosity and amount of granulating liquid, granulation time, impeller speed and compression pressure can affect granules as well as tablets properties (Fayed et al., 2017; Qusaj et al., 2012; Rahmanian et al., 2011; Santl et al., 2011). In addition, formulation variables can also influence the 
granule and tablet properties. Formulation variables can include type and amount of binders and diluents. This can be exemplified in cases whereby tablets formed from granules containing acacia as a binder had comparable hardness to that of sodium carboxymethyl cellulose, but lower than that of gelatin (Chime et al., 2013).

While the current literature has discussed processes and formulations of botanical materials based tablets, the tablets are typically prepared from the dried extract of botanical materials or botanical materials that have been milled to a fine powder. Tableting studies performed using coarse milled botanical materials, however, are relatively limited and unexplored. Tableting of coarse milled botanical materials may reduce the required milling energy. Also, tablets containing coarse milled botanical materials can provide similar mouth-feel consistency as botanical materials that are conventionally chewed for consumption. Therefore, the objectives of this work were to assess the feasibility of wet granulation to process coarse milled botanical materials for tableting and to evaluate the effect of formulation variability on the resultant tablet properties. Coarse milled botanical materials were defined in this study as milled botanical materials having a particle size of approximately 1-2 $\mathrm{mm}$.

\section{METHODS}

\section{Materials}

The diluents used in this study were microcrystalline cellulose (MCC; Avicel PH 101, FMC Biopolymer, Ireland) or mannitol (Singsino, China). Cinnamon bark was used as model botanical material of bark origin, and areca nut was used as model botanical materials of seed origin. The granulating liquid was made of maltodextrin (Glucidex IT 6, Roquette, France) dissolved in deionized water. Magnesium stearate (MgSt; M125, Productos Metalast, Spain) was used as the lubricant in tableting.

\section{Comminution of botanical materials}

The particle size of cinnamon bark and areca nut were reduced to 1-2 mm particle size. A jaw crusher mill (Fritsch, Germany) was used to perform initial size reduction of cinnamon bark. The milled cinnamon bark was subjected to further milling using a cone mill (Comil 197S, Idex-Quadro Engineering, Canada) installed with $2388 \mu \mathrm{m}$ aperture size grater screen and a round impeller with an edge, operated at $1350 \mathrm{rpm}$. Due to the inherent structural difference from cinnamon bark, milling of areca nut was initially performed using a hammer mill (M5A, Fitzmill@, Fitzpatrick, Canada) at a rotor speed of $2000 \mathrm{rpm}$, installed with $5 \mathrm{~mm}$ retention screen. The milled areca nut was subsequently milled using the cone mill with the same operating parameters as the milling of cinnamon bark.

\section{Compressibility of $\mathrm{MCC}$ and mannitol}

The compressibility of MCC and mannitol was evaluated based on the Heckel equation (Eq. 1) using the Analis software (AnalisMX v2.07.08). The Heckel equation evaluates a change in compact density with a change in compression pressure.

$$
\ln \left[\frac{1}{1-\mathrm{D}}\right]=\mathrm{KP}+\mathrm{A}
$$

Where $\mathrm{K}$ and A represent the gradient and $\mathrm{y}$-intercept of the linear portion of the Heckel plot, respectively. The yield pressure is obtained from reciprocal of the K. D and $\mathrm{P}$ represent the relative density and compression pressure, respectively. Relative density is obtained from the ratio between apparent density and true density of the materials. A helium pycnometer (PPY-14, Quantachrome Instruments, US) was used to determine the true density of the materials. The apparent density of the compact was subsequently calculated based on Eq. 2 .

Apparent density $=\frac{\text { compact weight }}{\pi \times(\text { compact radius })^{2} \times(\text { compact thickness })} \quad$ Eq. 2

The compaction was performed using a compaction simulator (Evolution Styl'One, Medelpharm, France). A $17 \mathrm{~mm}$ standard flat face punches and die set (Natoli Engineering Company, US) were used to form the compact. The upper and lower punch moved at a linear compression speed of 3.0 and $6.0 \mathrm{~mm} / \mathrm{s}$, respectively. At each compression cycle, $1000 \mathrm{mg}$ compact was formed. Evaluation of areca nut and cinnamon bark compressibility was also attempted. However, compacts made of areca nut or cinnamon bark alone were too weak for handling and measurement. As such, the only compressibility of MCC and mannitol was evaluated.

\section{Preparation of granules}

Compositions of areca nut granules and cinnamon bark granules are presented in Tables 1 and 2, respectively. The maltodextrin solution was prepared by dissolving maltodextrin in deionized water. Two different concentrations of maltodextrin solution were prepared; $25 \%$, w/w and $50 \%$, w/w. A planetary mixer (Major 250, Kenwood, UK) was used to perform wet granulation. The wet mass obtained was subsequently passed through a $4 \mathrm{~mm}$ aperture size screen. The resultant granules were oven-dried for 5 hours at $60{ }^{\circ} \mathrm{C}$.

\section{Analysis of granule size}

A representative sample of granules $(100 \mathrm{~g})$ was placed on series of sieves (Endecotts Ltd, UK) with $\sqrt{2}$ size progression and vibrated at $1 \mathrm{~mm}$ amplitude for 10 minutes (AS 200, Retsch, Germany). A cumulative undersize distribution curve was plotted using the weight of granules retained on each sieve to obtain $\mathrm{D}_{10}, \mathrm{D}_{50}$, and $\mathrm{D}_{90}$, which are granule sizes corresponding to the $10^{\text {th }}, 50^{\text {th, }}$ and $90^{\text {th }}$ weight percentiles. Weight fractions of granules 
Table 1. Formulation of areca nut granules

\begin{tabular}{|c|c|c|c|c|c|}
\hline \multirow[t]{2}{*}{$\begin{array}{l}\text { Formulation } \\
\text { code }\end{array}$} & \multirow[t]{2}{*}{$\begin{array}{l}\text { Areca nut } \\
(\%, w / w)\end{array}$} & \multicolumn{2}{|c|}{$\begin{array}{l}\text { Diluent } \\
(\%, w / w)\end{array}$} & \multicolumn{2}{|c|}{$\begin{array}{l}\text { The concentration of } \\
\text { maltodextrin solution }(\%, w / w)\end{array}$} \\
\hline & & MCC & Mannitol & $25 \%, w / w$ & $50 \%, w / w$ \\
\hline A1 & 66.7 & 33.3 & - & 15.0 & - \\
\hline A2 & 50.0 & 50.0 & - & 15.0 & - \\
\hline A3 & 33.3 & 66.7 & - & 15.0 & - \\
\hline A4 & 66.7 & - & 33.3 & - & 15.0 \\
\hline A5 & 50.0 & - & 50.0 & - & 15.0 \\
\hline A6 & 33.3 & - & 66.7 & - & 15.0 \\
\hline
\end{tabular}

with size $<2 \mathrm{~mm}, 2-4 \mathrm{~mm}$, and $>4 \mathrm{~mm}$ were also determined from the weight of granules retained on each sieve. Subsequent tableting and granule characterization (granule shape and friability) were performed on 2-4 $\mathrm{mm}$ size fraction granules.

\section{Preparation of tablets}

A representative granules sample with a size of $2-4$ $\mathrm{mm}$ from each formulation was used to form the tablets. Prior to compression, the granules were lubricated with $1 \%$, w/w MgSt. A manual tablet press (NP-RD10, Natoli Engineering Company, US) installed with 17 mm standard flat face tablet punches and die set (Natoli Engineering Company, US) was used to perform the compression. At each compression, tablet, each weighing $1000 \mathrm{mg}$, was produced. The tablets were prepared at compression pressures of 88,132 , and $176 \mathrm{MPa}$.

\section{Characterization of granules}

\section{Analysis of granule shape}

A stereomicroscope (SZ61, Olympus, Japan) equipped with a DP Controller software (Version 2002- 2007, Olympus, Japan) and an attached camera (DP71, Olympus, Japan) was used to capture the image of at least 625 granules from each formulation. The obtained granule roundness and aspect ratio was subsequently analyzed using Image-pro 6.3 software (Version 6.3.0.512, Media Cybernetics, Inc, US) based on Eqs. 3 and 4 , respectively.

$$
\begin{aligned}
& \text { Roundness }=\frac{(\text { Perimeter })^{2}}{4 \times \pi \times(\text { Area })} \\
& \text { Aspect ratio }=\frac{\text { Length }}{\text { Breadth }}
\end{aligned}
$$

\section{Evaluation of granule friability}

Granule friability was assessed using a friabilator (TA 20, Erweka GmbH, Germany). A representative sample of granules $(5 \mathrm{~g}), \mathrm{W}_{\mathrm{T}}$, were tumbled with 20 steel balls (diameter of each ball: $6 \mathrm{~mm}$ ) for 250 revolutions. After tumbling, the granules were passed through a $2 \mathrm{~mm}$ aperture size sieve, and the weight of granules retained on the sieve $\left(\mathrm{W}_{\mathrm{R}}\right)$ was recorded. Friability index was subsequently calculated using Eq. 5.

$$
\text { Friability index }(\%)=\left(\frac{\mathrm{W}_{\mathrm{T}}-\mathrm{W}_{\mathrm{R}}}{\mathrm{W}_{\mathrm{T}}}\right)
$$

\section{Characterisation of tablets}

\section{Evaluation of tablets tensile strength}

Tablet tensile strength was calculated according to Eq. 6.

$$
\text { Tensile strength }=\frac{2 \times(\text { tablet hardness })}{\pi \times(\text { tablet diameter }) \times(\text { tablet thickness })}
$$

A hardness tester (TBF 1000, Copley Scientific, UK) was used to obtain tablet hardness and diameter. A thickness gauge (ID-C1012 EXBS, Mitutoyo, Japan) was used for the measurement of tablet thickness.

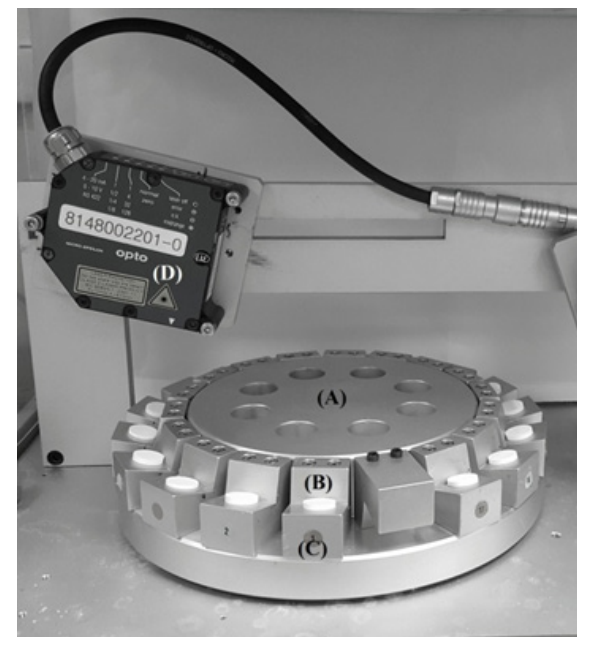

Figure 1. The photograph shows a rotating turntable $(\mathrm{A})$ with tablets $(\mathrm{B})$ placed on platforms $(C)$ affixed to the rotating turntable. Laser displacement sensor (D) allows measurement of tablet surface roughness as the tablets passed under the laser 
(Ai)

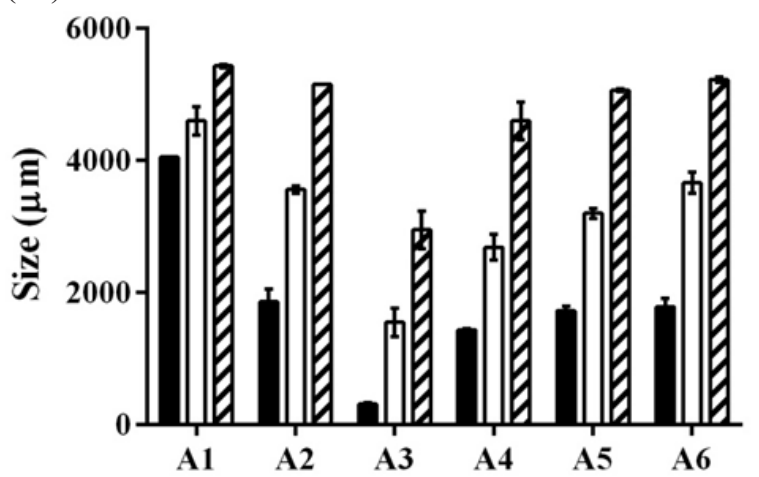

(Bi)

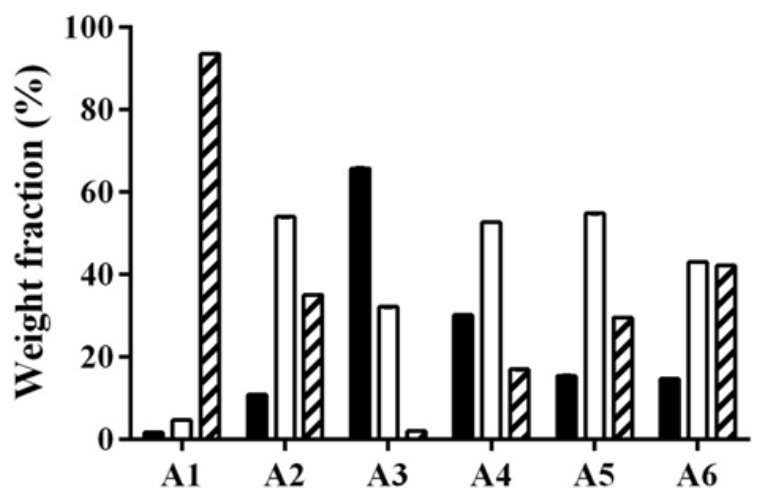

(Aii)

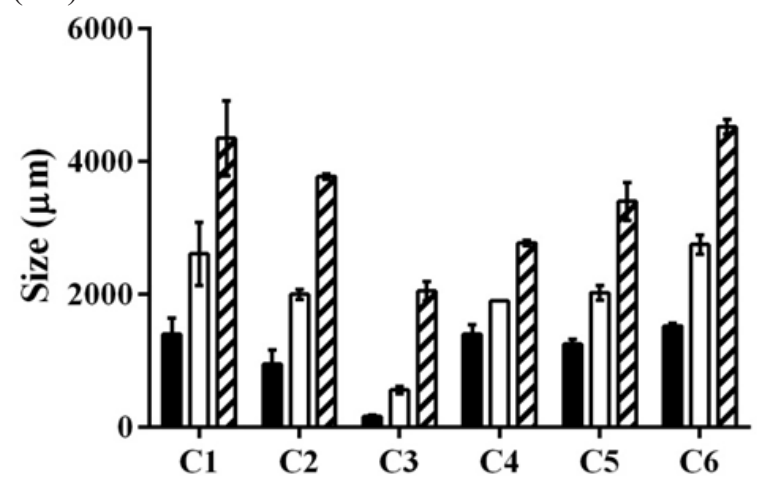

(Bii)

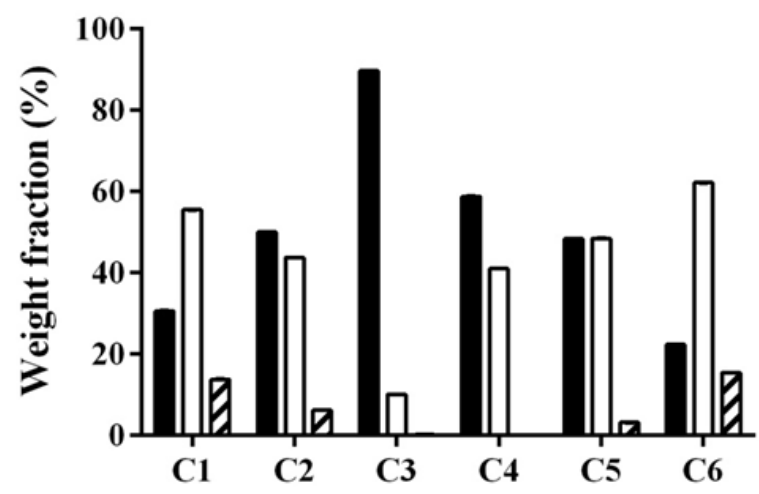

Figure 2. Effect of formulation variables on granule size. (A) Granule size of different formulations; (i) areca nut and (ii) cinnamon bark granules. $D_{10}, \square D_{50}$ and $\mathbb{Z} D_{90^{\circ}}$ (B) Granule size weight fraction of different formulations; (i) areca nut and (ii) cinnamon bark granules. $\square 2 \mathrm{~mm}, \square 2-4 \mathrm{~mm}$ and $\mathbb{Z}>$ $4 \mathrm{~mm}$ size fraction

\section{Evaluation of tablets surface roughness}

Tablet surface roughness was analyzed using a calibrated laser displacement sensor (OptoNCDT 1700-20, MicroEpsilon, Germany) fitted in an instrument comprising a turntable (Figure 1). The evaluation was performed on tablets prepared at $176 \mathrm{MPa}$ compression pressure. The tablets were placed on the turntable rotating at 0.2 $\mathrm{rpm}$. The surface roughness was estimated by measuring the distance between the tablet surface and the laser using the laser displacement sensor. MATLAB program (R2010a, The MathWorks, USA) was used to process the data and to obtain the mean surface roughness values of the tablets. Surface roughness was also evaluated for tablets containing only diluents; MCC or mannitol.

\section{RESULTS AND DISCUSSION}

Effect of formulation variables on granules properties Granules produced were assessed for their size, shape, and friability. The size of granules from different formulations was shown in Figure 2. In general, granules produced using areca nut were slightly larger than granules prepared from cinnamon bark. For both botanical materials, when MCC was used as a diluent, an increasing amount of MCC produced granules of smaller size. This was evident from $\mathrm{D}_{10}$ to $\mathrm{D}_{90}$ graphs (Figure 2A) and granule size weight fraction (Figure 2B). With more MCC in the formulations, there were a greater fraction of granules having a size smaller than $2 \mathrm{~mm}$. In contrast to MCC, an increasing amount of mannitol produced granules of larger size. The effect of mannitol on granule size was more prominently observed in granules made from cinnamon bark.

The contrasting trend observed could be explained by the behavior of the diluent during wet granulation. MCC is hygroscopic in nature but insoluble in water. Mannitol, on the other hand, is non-hygroscopic and has poor wettability (Rowe et al., 2009). Due to the ability of MCC to take in water into the internal structure, with an increasing amount of MCC in the formulation, the amount of granulating liquid or water available for particle agglomeration was lesser. Consequently, smaller granules were produced. As mannitol does not take in water, the availability of granulating liquid for particle agglomeration was relatively unchanged regardless of the mannitol amount. It follows that amount of mannitol in the formulation had minimal influence on the granule size. This also explained the higher maltodextrin concentration needed for granulation 
(A)

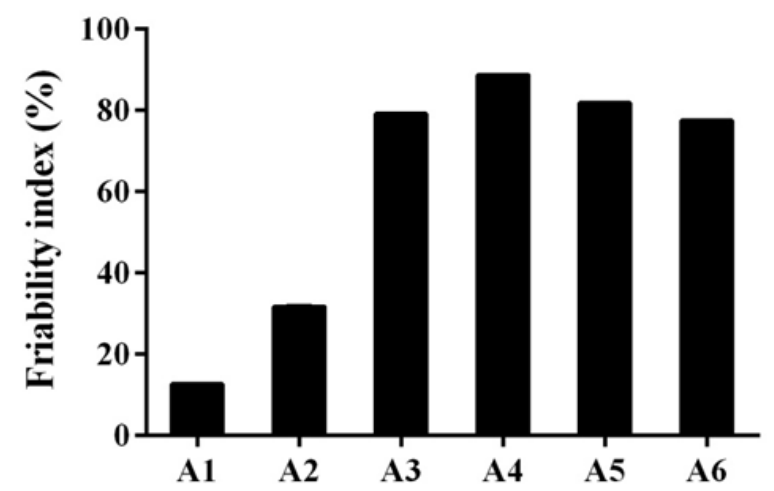

(B)

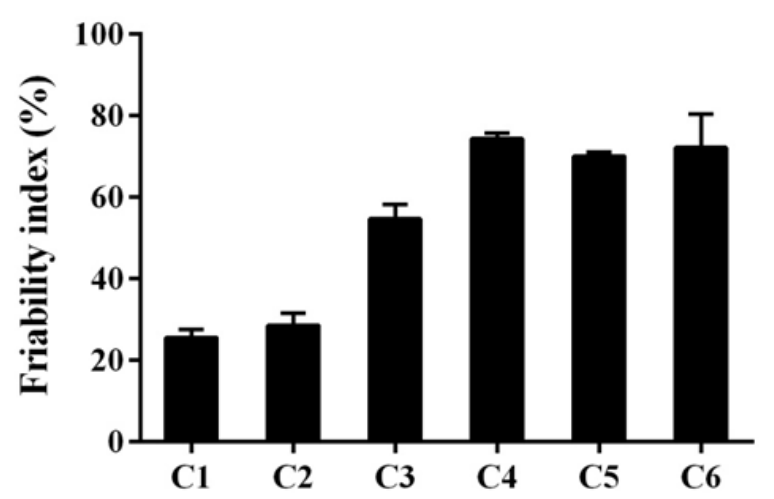

Figure 3. Effect of formulation variables on granule friability (A) Areca nut granules (B) Cinnamon bark granules

in formulations containing mannitol. Granulation of mannitol using the same maltodextrin concentration as in MCC granulation resulted in an over-wetted wet mass that was too wet for subsequent processing and handling. This observation highlighted that diluent used in the granulation could also influence the amount of granulating liquid available for particle agglomeration. Indeed, the amount of granulating liquid has been shown to affect granule growth and agglomeration. With greater availability of water for agglomeration, liquid saturation of the granules increased with resultant improvement in granules coalescence. Also, higher liquid saturation results in more deformable granules and more free liquid at the granule surface. Consequently, increasing the chance of granule coalescence upon collision, hence increasing granule size (Badawy et al., 2012; Fayed et al., 2017; Pandey et al., 2013).

Results from the friability study were shown in Figure 3. Friability was assessed using the friability index. The higher the friability index, the more friable is the granule. Generally, areca nut produced granules of relatively higher friability than cinnamon bark. From the assessment of diluent types and granule friability, it was observed that MCC produced granules of lower friability than mannitol. This could possibly be due to the relatively weaker inter-particle bonding of mannitol as compared to MCC. Results from different ratios of diluent to botanical material revealed that with an increasing amount of MCC in the formulation, granule friability increased. This could be explained by a lack of granulating liquid for particle coalescence and agglomeration. Also, lesser granulating liquid may result in the formation of a weaker inter-particle bond. In contrast, the influence of mannitol amount to botanical materials on the friability, however, was minimal.

Granule shape was evaluated based on aspect ratio and roundness values. The results were presented in Figure
4. All formulations had comparable aspect ratio and roundness values, indicating that granule shape was less affected by variability in the formulations. The aspect ratio and roundness values that deviated greatly from 1 could be because of the coarse and irregular shape of the coarse milled botanical materials. Additionally, the particle size of the milled botanical materials was much larger than the diluents; MCC or mannitol. It followed that a larger amount of diluents might be needed to produce rounder granules.

\section{Effect of formulation variables on tablet tensile strength}

Figure 5 showed the tensile strength of tablets produced from the granules of different formulations. Generally, higher compression pressure produced tablets with higher tensile strength. Overall, areca nut granules (Figure 5A) resulted in tablets of lower tensile strength than cinnamon nut granules (Figure 5B), possibly due to the inherent difference in properties of the nut and bark based botanical materials. Comparison of botanical material ratio to diluent revealed that with an increasing diluent amount in the formulation, tablets tensile strength increased. This result further highlighted that the botanical material alone was lack bonding strength that was needed to keep the tablets intact. Therefore, the addition of diluent into the formulation is necessary to confer bonding strength to the tablets.

For both botanical materials, tablets containing MCC had higher tensile strength than that of mannitol. This trend was observed across all compression pressures. This could be explained by differences in the deformation behavior of the diluent as assessed from yield pressure. The yield pressures were 53.9 $\pm 0.3 \mathrm{MPa}$ and $109.6 \pm$ 1.4 MPa for MCC and mannitol, respectively. The lower yield pressure of MCC agreed with existing findings on the plastically deforming behavior of MCC (Ilic et al., 2013). For plastically deforming materials, the 
(Ai)

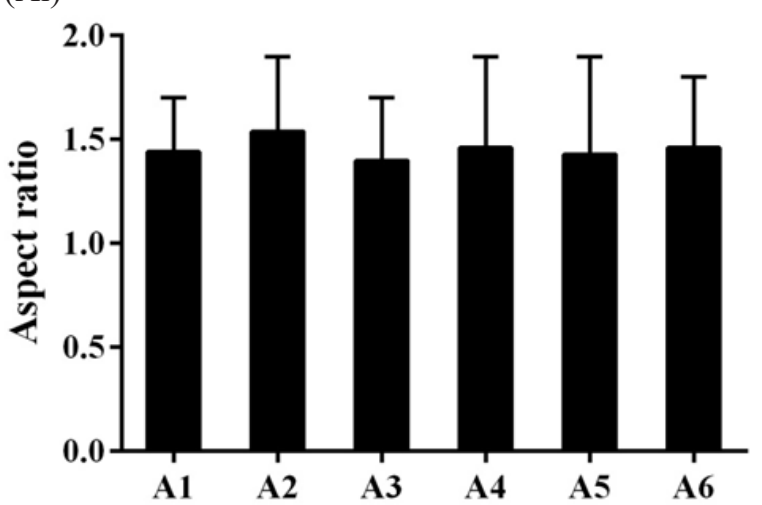

(Bi)

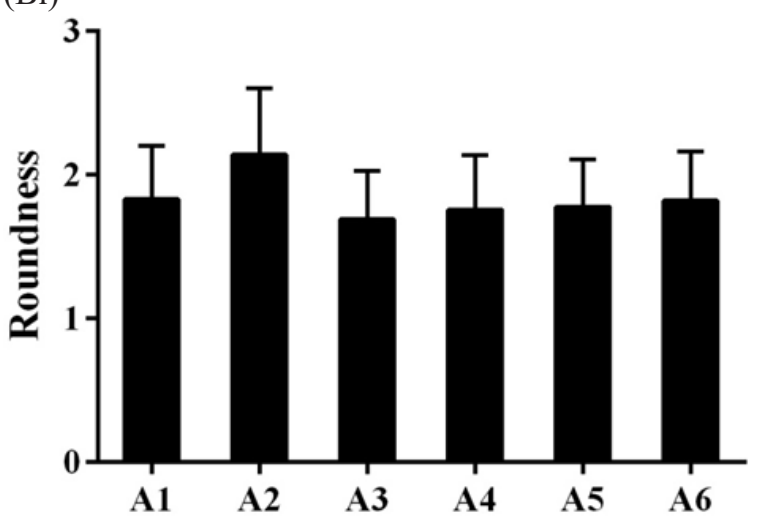

(Aii)

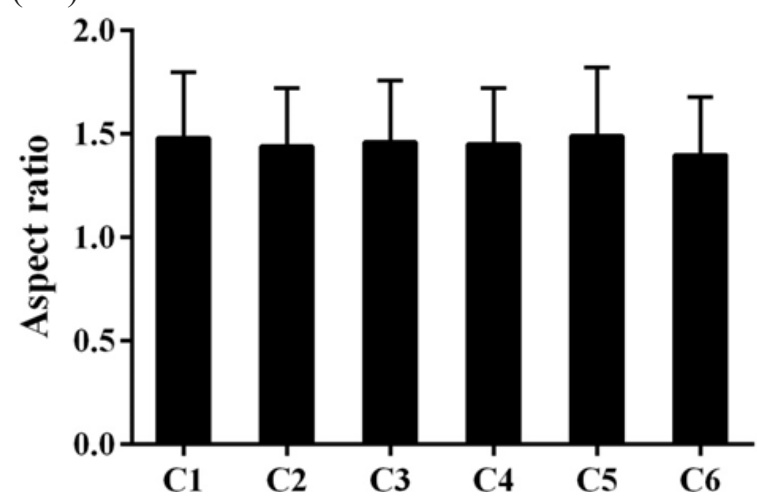

(Bii)

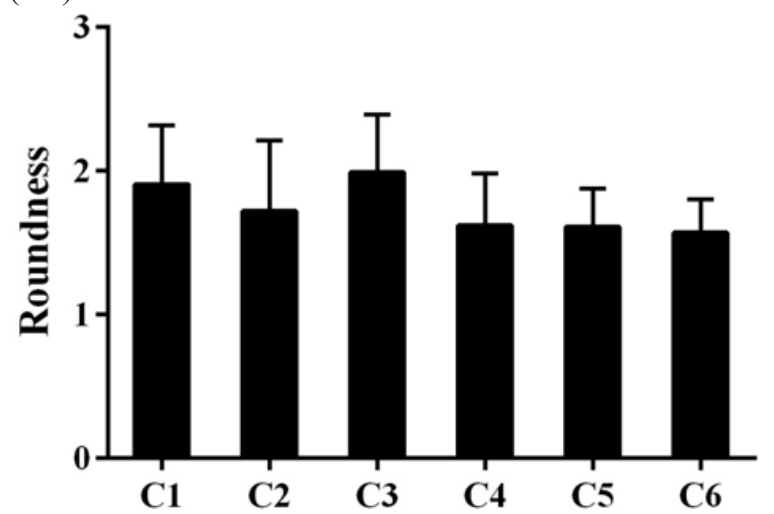

Figure 4. Effect of formulation variables on granule shape. (A) The aspect ratio of (i) areca nut and (ii) cinnamon bark granules. (B) The roundness of (i) areca nut and (ii) cinnamon bark granules

(A)

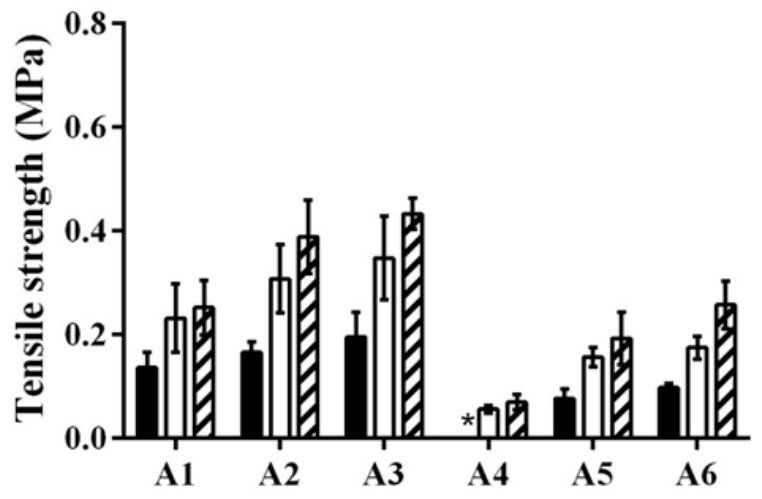

(B)

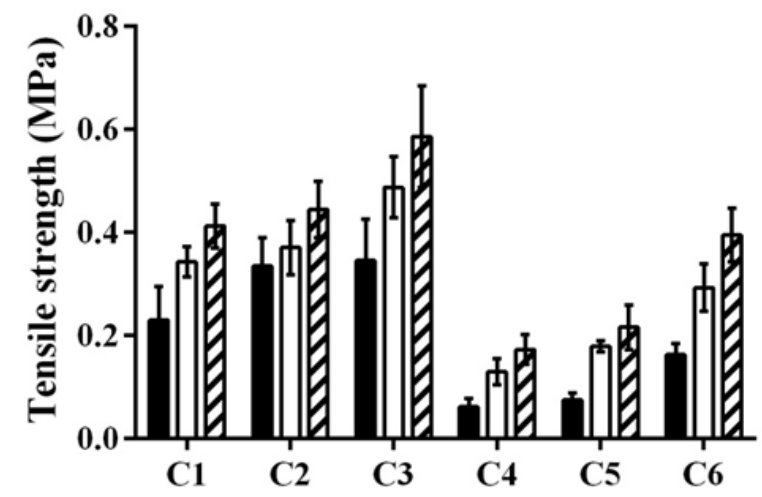

Figure 5. Tensile strength of tablets prepared from (A) areca nut and (B) cinnamon bark granules with compression pressures of $88 \mathrm{MPa}, \square 132 \mathrm{MPa}$, and $\square 176 \mathrm{MPa}$. * Tablets were too weak for measurement

materials deformed during compression and retained the deformed shape during the decompression stage. As a result, a larger bonding area is formed. On the other hand, mannitol is known to undergo brittlefragmentation during compression (Tarlier et al., 2018). While fragmentation can increase the bonding area, mannitol lacks plastic deformation. Additionally, fragmented materials mainly undergo elastic deformation. For elastically deformed materials, the deformed materials return to its original size and shape as compression pressure is removed. Consequently, the bonding area formed during compression does not survive the decompression stage. Local stress higher than the materials' yield strength is needed to form a higher bonding area for brittle-fragmenting materials. Hence, the higher yield pressure of mannitol. The results also showed increasing tablet tensile strength with increasing MCC or mannitol amount. This was due to 
(A)

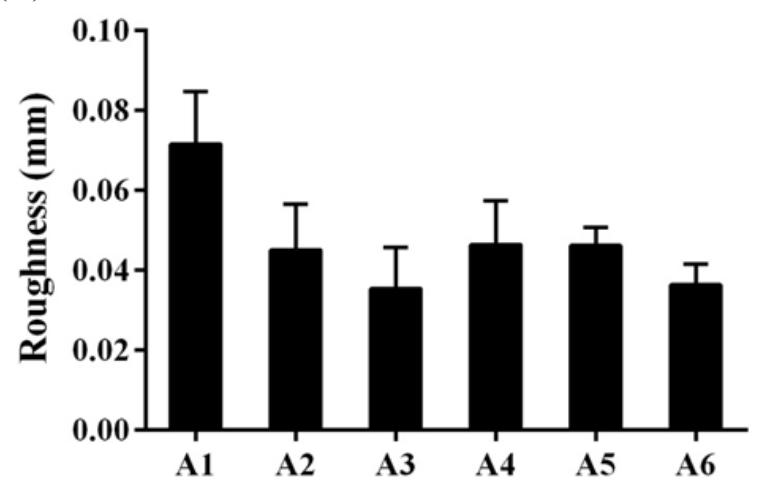

Figure 6. The surface roughness of tablets made from

more extensive bond formation with a greater amount of diluent, thereby imparting strength to the tablets. Clearly, the deformation behavior of diluents can affect tablet tensile strength.

Tablet tensile strength might also be influenced by granule friability, as evident in MCC based granules. Although granules with a higher amount of MCC were more friable, the granules formed tablets of higher tensile strength. Granules with higher friability are likely to break down into smaller particles under compression pressure, creating more bonding area, hence higher tensile strength. This trend, however, was less apparent in mannitol based granules. Although the friability of mannitol granules was comparable for the different formulations, higher tensile strength was observed for tablets prepared from granules containing a higher amount of mannitol.

\section{Effect of formulation on tablets surface roughness}

Tablets surface roughness might be critical in subsequent tablet processing such as coating as well as the production of tablets with acceptable mouthfeel. Given the relatively large starting particle size of the granules $(1-2 \mathrm{~mm})$, the production of tablets with smooth surfaces can be challenging. Figure 6. showed mean surface roughness values of cinnamon bark and areca nut tablets. The higher the roughness value, the rougher was the surface. While the roughness values were not substantially different, general trends could be observed. Results showed that the surface of MCC based tablets was generally rougher than mannitol based tablets. This was further supported by a lower roughness value of mannitol only tablets without the addition of any botanical materials as compared to MCC only tablets. The roughness values were $0.0118 \pm 0.001 \mathrm{~mm}$ and $0.0108 \pm 0.002 \mathrm{~mm}$ for MCC and mannitol only tablets, respectively. This could possibly be attributed to the brittle-fragmenting behavior of mannitol. Under compression pressure, mannitol experienced a greater extent of fragmentation and produced more fine particles that possibly filled the tablet surface concavities.
(B)

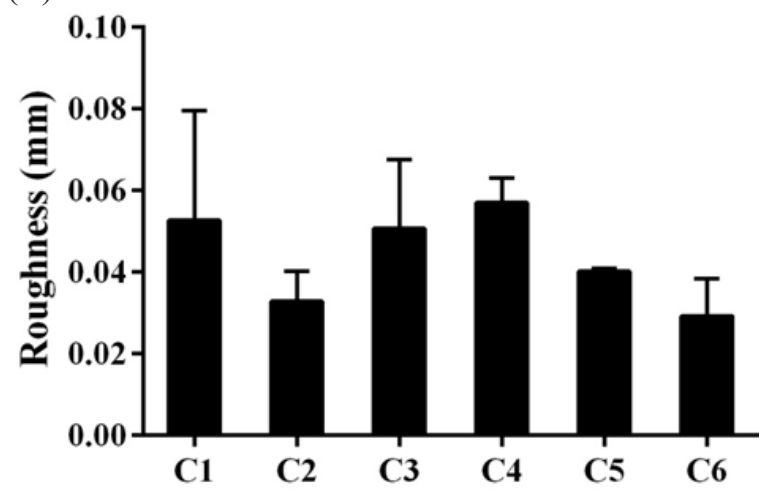

Comparison of tablets surface formulated with different ratios of botanical material to diluent revealed that tablets formed from granules composing of more botanical materials had rougher surface. This could be due to the coarse and irregular shape of the coarse milled botanical materials. Therefore, the addition of diluents was useful to reduce surface roughness. Diluents could achieve closer packing and fill gaps in between coarse botanical materials owing to their comparatively smaller particle size as compared to the coarse botanical materials. As such, the addition of diluents not only improved tableting properties of the formulation but also facilitated the formation of smoother tablet surface.

Certain formulations, however, did not follow the general trend. This was seen in A4 and A5, which had comparable surface roughness, although A4 was formulated with more areca nut material. This could suggest that mannitol in the formulation might not be sufficient to smoothen out the surface. This was supported by a reduction in the roughness value when more mannitol was added to the formulation, as seen in A6. Another formulation, C3, had higher surface roughness than C2, although C3 had lower cinnamon bark material. This could be attributed to relatively lesser MCC found in $\mathrm{C} 3$ granules. As explained earlier, the higher MCC amount in the formulation reduced the amount of granulating liquid for particle coalescence. This observation, however, was not seen in areca nut-based formulation. Therefore, suggesting that properties of botanical materials and diluents might affect tablets roughness. Also, the amount of diluent needed to produce tablets of certain roughness could be affected by types of botanical materials.

\section{CONCLUSION}

Botanical materials based tablets were prepared using granules containing coarse milled cinnamon bark or areca nut. This study showed the viability of using wet granulation as a pre-processing step to prepare tablets from coarse milled botanical materials. It was also demonstrated that the physical properties of the tablets 
could be affected by the types of diluent, botanical material as well as the ratios of botanical material to diluent in the formulation. Overall, tablets produced from granules containing MCC had higher tensile strength and rougher surface. In contrast, tablets formed from granules consisting of mannitol were found to have a smoother surface with lower tensile strength. Findings from this study highlighted that the understanding of the tableting behavior of diluents and botanical materials would be useful for the rational design of tablets made from coarsely milled botanical materials.

\section{ACKNOWLEDGMENT}

The authors would like to acknowledge the financial support from GEA-NUS PPRL fund.

\section{REFERENCES}

Alamgir, A. N. M. (2017). Herbal drugs: their collection, preservation, and preparation; evaluation, quality control, and standardization of herbal drugs Therapeutic use of medicinal plants and their extracts: volume 1: Pharmacognosy (pp. 453-495). Cham: Springer International Publishing.

Badawy, S. I., Narang, A. S., LaMarche, K., Subramanian, G., \& Varia, S. A. (2012). Mechanistic basis for the effects of process parameters on quality attributes in high shear wet granulation. International journal of pharmaceutics, 439(1-2), 324-333.

Bernatoniene, J., Petkeviciute, Z., Kalveniene, Z., Masteikova, R., Draksiene, G., Muselik, J., . . . \& Savickas, A. (2010). The investigation of phenolic compounds and technological properties of Leonurus, Crataegus and Ginkgo extracts. Journal of medicinal plants research, 4(10), 925-931.

Chandira, M., \& Jayakar, B. (2010). Formulation and evaluation of herbal tablets containing Ipomoea Digitata Linn. extract. International journal of pharmaceutical sciences review and research, 3(1), 101-109.

Chime, S. A., Ugwuoke, E. C., Onyishi, I. V., Brown, S. A., \& Onunkwo, G. C. (2013). Formulation and evaluation of Alstonia boonei stem bark powder tablets. Indian journal of pharmaceutical sciences, 75(2), 226230 .

Cvetanovic, A., S, M., Zekovic, Z., Ž, L., Vidovic, S., \& Radojković, M. (2011). Antioxidant properties of tablets prepared from ginkgo, chinacea and mentha dry extracts. Romanian biotechnological letters, 16, 6481-6487.

Fayed, M. H., Abddel-Rahman, S. I., Alanazi, F. K.,
Ahmed, M. O., Tawfeek, H. M., \& Ai-Shedfat, R. I. (2017). High-shear granulation process: influence of processing parameters on critical quality attributes of acetaminophen granules and tablets using design of experiment approach. Acta poloniae pharmaceutica drug research, 74(1), 235-248.

Ilic, I., Govedarica, B., Sibanc, R., Dreu, R., \& Srcic, S. (2013). Deformation properties of pharmaceutical excipients determined using an in-die and out-die method. International journal of pharmaceutics, 446(12), 6-15.

Li, Z., Wu, F., Zhao, L., Lin, X., Shen, L., \& Feng, Y. (2018). Evaluation of fundamental and functional properties of natural plant product powders for direct compaction based on multivariate statistical analysis. Advanced powder technology, 29(11), 2881-2894.

Pandey, P., Tao, J., Chaudhury, A., Ramachandran, R., Gao, J. Z., \& Bindra, D. S. (2013). A combined experimental and modeling approach to study the effects of high-shear wet granulation process parameters on granule characteristics. Pharmaceutical development and technology, 18(1), 210-224.

Parikh, D. M. (2016). Granulation of plant products and nutraceuticals. Handbook of pharmaceutical granulation, 349-363.

Qusaj, Y., Leng, A., Alshihabi, F., Krasniqi, B., \& Vandamme, T. (2012). Development strategies for herbal products reducing the influence of natural variance in dry mass on tableting properties and tablet characteristics. Pharmaceutics, 4(4), 501-516.

Rahmanian, N., Naji, A., \& Ghadiri, M. (2011). Effects of process parameters on granules properties produced in a high shear granulator. Chemical engineering research and design, 89(5), 512-518.

Rowe, R. C., Sheskey, P. J., \& Quinn, M. E. (2009). Handbook of pharmaceutical excipients R. C. Rowe, P. J. Sheskey \& M. E. Quinn. (Eds.)

Santl, M., Ilic, I., Vrecer, F., \& Baumgartner, S. (2011). A compressibility and compactibility study of real tableting mixtures: the impact of wet and dry granulation versus a direct tableting mixture. International journal of pharmaceutics, 414(1-2), 131-139.

Shanmugam, S. (2015). Granulation techniques and technologies: recent progresses. Bioimpacts, 5(1), 55-63.

Sun, F., Xu, B., Zhang, Y., Dai, S., Yang, C., Cui, X., . . . \& Qiao, Y. (2016). Statistical modeling methods to 
analyze the impacts of multiunit process variability on critical quality attributes of Chinese herbal medicine tablets. Drug design development and therapy, 10, 39093924.

Tarlier, N., Soulairol, I., Sanchez-Ballester, N., Baylac, G., Aubert, A., Lefevre, P., . . \& \& Sharkawi, T. (2018). Deformation behavior of crystallized mannitol during compression using a rotary tablet press simulator. International journal of pharmaceutics, 547(1-2), 142149.

Yi, W., \& Wetzstein, H. Y. (2011). Effects of drying and extraction conditions on the biochemical activity of selected herbs. HortScience, 46(1), 70-73. 